Article

\title{
Optimisation of Storage for Concentrated Solar Power Plants
}

\author{
Luigi Cirocco $^{1, *}$, Martin Belusko ${ }^{2}$, Frank Bruno ${ }^{2}$, John Boland ${ }^{1}$, Peter Pudney ${ }^{1}$ \\ ${ }^{1}$ Centre for Industrial and Applied Mathematics, School of Information Technology and Mathematics, \\ University of South Australia, Mawson Lakes Boulevard, Mawson Lakes, SA 5095, Australia; \\ E-Mails: John.Boland@unisa.edu.au (J.B.); Peter.Pudney@unisa.edu.au (P.P.) \\ 2 Barbara Hardy Institute, University of South Australia, Mawson Lakes Boulevard, Mawson Lakes, \\ SA 5095, Australia; E-Mails: Martin.Belusko@unisa.edu.au (M.B.); \\ Frank.Bruno@unisa.edu.au (F.B.) \\ * Author to whom correspondence should be addressed; E-Mail: luigi.cirocco@mymail.unisa.edu.au; \\ Tel.: +61-8-8302-5781; Fax:+61-8-8302-5785
}

External Editor: Andreas Manz

Received: 10 October 2014; in revised form: 1 December 2014 / Accepted: 2 December 2014 / Published: 12 December 2014

\begin{abstract}
The proliferation of non-scheduled generation from renewable electrical energy sources such concentrated solar power (CSP) presents a need for enabling scheduled generation by incorporating energy storage; either via directly coupled Thermal Energy Storage (TES) or Electrical Storage Systems (ESS) distributed within the electrical network or grid. The challenges for $100 \%$ renewable energy generation are: to minimise capitalisation cost and to maximise energy dispatch capacity. The aims of this review article are twofold: to review storage technologies and to survey the most appropriate optimisation techniques to determine optimal operation and size of storage of a system to operate in the Australian National Energy Market (NEM). Storage technologies are reviewed to establish indicative characterisations of energy density, conversion efficiency, charge/discharge rates and costings. A partitioning of optimisation techniques based on methods most appropriate for various time scales is performed: from "whole of year", seasonal, monthly, weekly and daily averaging to those best suited matching the NEM bid timing of five minute dispatch bidding, averaged on the half hour as the trading settlement spot price. Finally, a selection of the most promising research directions and methods to determine the optimal operation and sizing of storage for renewables in the grid is presented.
\end{abstract}


Keywords: concentrated solar power; energy storage systems; thermal energy storage; optimisation

\section{Research Background}

Australia's and the world's use of fossil fuels is unsustainable with Australia having an abundance of renewable energy sources, particularly solar irradiation. We need to imagine, design and transition to a future where electricity is effectively generated from Renewable Energy (RE) sources. The solution will require a mix of scalable renewable generation technologies, demand management and energy storage.

Concentrated Solar Power (CSP) plants are a form of RE generation where solar radiation falling on a large area ranging from a few hundred to hundreds of thousands of square metres is focused or concentrated onto a significantly smaller receiver area, up to several thousand times smaller than the collection area. At the receiver this concentrated energy can be harnessed as heat to generate steam for the production of electrical power via a steam turbine driven generator, as would any traditional fuel driven steam-electric power plant such as a coal fired or nuclear power station. Although there are many realisations of CSP plants based on this simple design principle throughout the world, research is still required to enhance the designs for operation within a specific region. This requirement is driven by variances in the intermittent solar resource and energy demands, as well as on the economic environment and the opportunities for profit making within the energy market framework of the specific region.

In Australia CSP has the potential to be a substantial contributor to electricity generation as the output from such plants correlates well to the daytime electricity demand. In order to meet demand when the sun is obscured by cloud and some or all of the night time demand, a CSP plant can be designed with Thermal Energy Storage (TES) where excess energy at the receiver may be re-directed to storage, via intermediary systems, for later use in steam generation. Once again there are realisations of CSP with TES worldwide but few if any have been fine tuned to meet their particular climatic, energetic and economic environments. Further research is required in determining not only the optimal sizing but also the specific operational paradigms and control systems for such plants in the Australian context.

With growing levels of RE penetration and with the further distribution of variable generation as imposed by the growth of residential rooftop Photo-Voltaic (PV) into the electrical supply grid, maintaining grid stability is emerging as a critical problem in the short term. With research into this problem being in its infancy in countries such as the US and Spain, the opportunity exists for directed research to address this problem in the Australian context.

To date, studies involving generation from $100 \%$ RE depend on arguably excessive and economically incredulous amounts of storage. As such studies primarily involve meeting energetic demand under variable generation in RE supply, research is required to investigate an optimal and robust control strategy before the determination of the minimum quantity of storage such that local demand is met and grid stability is maintained.

Furthermore, research into hybridised storage for CSP where TES and Electrical Storage Systems (ESS) are controlled from the one plant is also lacking despite extensive research into ESS storage options for other VG RE sources such as wind and PV generation. ESS such as utility scale batteries 
or Pumped Hydro Storage (PHS) where water is moved back into the upper reservoir lake when supply energy exceeds demand would greatly enhance the options available to a CSP plant for storage. Future research should consider the incorporation of ESS with CSP as it may prove advantageous despite there being no identified literature considering a CSP with both TES and ESS.

Figure 1 as adapted from Figure 2.1 [1] and Figure 16.6 [2], depicts a generalised CSP plant that incorporates TES with electrical heaters and ESS for electricity buy-back in the plant design. Such a plant would then participate in the supply of electricity to the grid within the Australian National Energy Market (NEM), bidding for the generation of power and associated services in accordance with the National Electricity Rules [3]. Essentially this market requires bids for the dispatch of energy to be placed every 5 minutes, with the spot price to be paid to suppliers by consumers being the average of the last six bids as cleared every half hour.

Figure 1. General Overview of Energy Conversion Blocks for Concentrated Solar Power, adapted $[1,2]$

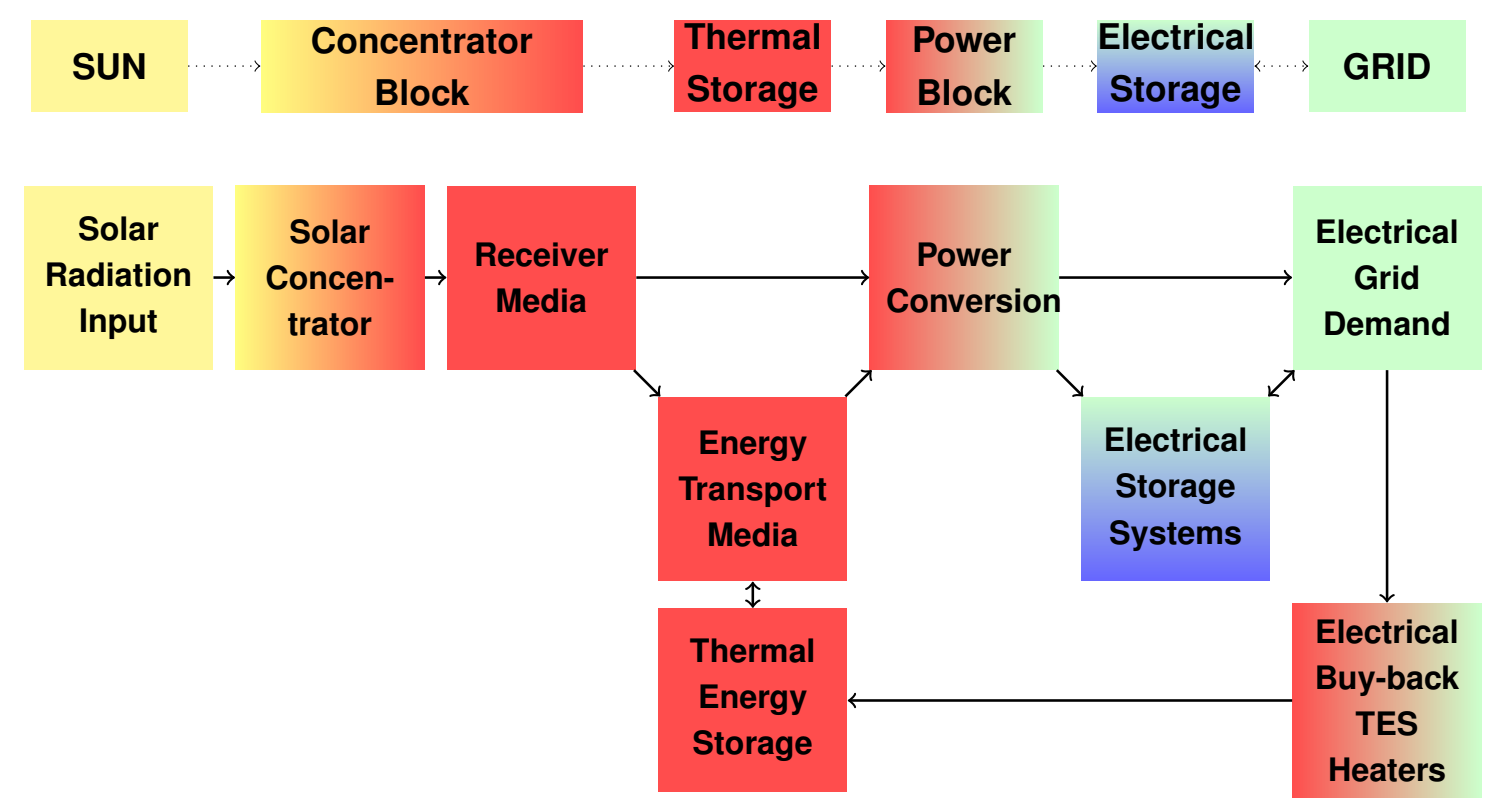

The remainder of this article will present relevant works used to formulate the research problem and present possible future research to be undertaken in order to develop optimal robust operation and control with minimal sizing of CSP with storage.

\section{Survey of Relevant Works}

\subsection{Introduction}

This section presents a survey of the literature conducted in order to achieve an understanding of the problem domain and to set the research direction. The section is in three major parts: the first will identify background information relating renewable energy technologies and frame the problem for CSP plants within this context; the second part will then discuss research into electricity generation with CSP with TES and ESS with the goal to provide a concise index to the elements for the operation of a CSP system and the environment in which it would operate (What to model and why?); the third part presents 
a review of the modelling and optimisation methods applicable to CSP with storage within the renewable energy domain (How to model and optimise.).

\subsubsection{Renewable Energy Domains: An Overview}

In order to achieve an appropriate operational model for CSP plant with storage, the RE landscape and the varied RE technologies need to be acknowledged, even if they are not incorporated into the model explicitly, this knowledge allows for a more holistic perspective. The collection preface by Sayigh [4] presents an overview of the RE research landscape worldwide, identifying an eight volume partitioning of various RE domains, namely:

Photo-Voltaic,

Wind,

Solar Thermal,

Fuel Cells and Hydrogen Technology,

Biomass and Biofuels,

Hydro,

Geothermal and

Oceanic Power

Within this partitioning CSP with storage is one element of the "Solar thermal" grouping offering utility scale electricity generation in the order of hundreds of mega Watts (MW) using the same or similar generator technology as conventional fossil fuel or nuclear powered power stations, without the ongoing fuel costs, Green House Gas (GHG) emissions and waste disposal issues.

As CSP plants continue to use conventional power generation from heated steam some designs have hybridised the heat sources currently incorporating heating elements that burn either a mineral gas or biofuel such that the plant can operate for a larger proportion of time especially during times of low irradiation, i.e., winter days; an analysis of such a plant is presented by Usaola [5].

Furthermore when considering ESS for CSP storage there is a large body of knowledge in the PV and Wind domains which could be applied to investigations for CSP.

Hydro-electric power generation also has a considerable body of knowledge relating to it and bears some similarity to the operation of CSP with storage, albeit the supply of rain water is on an annual cycle rather than a daily one for sunlight. When TES with buy-back heating is considered for a CSP with storage the plant then resembles PHS, where energy can be bought in at favourable prices, stored and then used to generate at some later time when market conditions are more favourable (or profitable) thus enabling an arbitrage mechanism for profit making (buy low, sell high), this mechanism is investigated in Kim and Powell [6] for the operation of wind farms with associated PHS and more recently in Cruise et al. [7] where optimal control of PHS was studied based on detailed mathematical models of both the store and market dynamics when operating in the UK's National Grid.

\subsubsection{CSP with Storage: Framing the Problem}

Traditionally the terms "baseload" and "peaking" have been used in the electrical power generation industry to refer to an operational paradigm where grid security is achieved through having enough 
generation installed to meet the average (or baseload) and spurious peaks (or peaking) in demand that may occur for only a small percentage of the time in a yearly cycle. With the advent of greater penetration of semi-scheduled RE generators into the grid, namely large scale wind farms and residential PV, and improved Demand Side Participation (DSP) for Commercial and Industrial (C\&I) participants and of the residential consumer on the horizon the AEMC report "Power of choice review-giving consumers options in the way they use electricity" [8] this paradigm is being challenged and a new common vocabulary for power distribution needs to be established. In order to provide a reliable energy supply grid Denholm et al. [9] suggest the existing "variability" in demand needs to be better matched to that from RE sources by increasing their "dispatchability" as is made possible by CSP with TES.

Within Australia a recent publication from the Australian Bureau of Resources and Energy Economics (BREE) “Australian Energy Projections to 2049-50" Table 11 [10], projects the supply of electricity from RE sources to be $51 \%$ of the total projected demand by 2050 with wind to provide $21 \%$, solar (both PV and thermal) $16 \%$, geothermal about $8 \%$ and hydro output about $5 \%$, as the capacity of hydro is expected to remain constant at current levels.

The categorisation of power generating plants is presented as being either "base-load", "peak-load" and "mid-merit" or "intermediate", [11] Box 1.

Base-load plants can generate electricity at lower cost per unit generation, typically stated in dollars per Watt-hours $(\$ / W h)$ but lack the ability to respond to large changes in demand, either increasing or decreasing. In the context of energy market trading base load plants may bid at negative spot prices when demand decreases rapidly in order to maintain output stability in the short term.

Peak-load plants, as the name suggests are often implemented as gas fired turbines (GFT) and are able to power up in a matter of minutes to meet large spikes in demand. Within the context of energy market trading these plants can also attract premium prices for meeting these upward spikes with peak plants typically only operating for short periods and thus incurring only minimal fuel, operation and maintenance costs.

Hydro power is often categorised as mid-merit or intermediate, as such plants can respond rapidly to changes in demand in both directions but often have objectives and constraints unrelated to energy generation including supplying potable water and controlling flood water outflow to downstream waterways. Such plants are often play a role in stabilizing grid frequency and assist in meeting ramp rate changes in the ancillary services market of the NEM framework.

In scenarios with higher and higher penetration of RE sources such as PV and wind, one possible avenue of investigation is that CSP with TES can offer a service akin to that provided by outflow only hydroelectric plants not only provide scheduled generation but more importantly, grid stabilisation ancillary services through an ability to rapidly respond to changing system dynamics. In addition, when coupled with some level of ESS or TES fitted with buyback heaters such plants would have the added versatility of providing a utility size regenerative breaking element capable of harnessing energy that would otherwise be wasted from either traditional fossil fuel based or other RE systems, especially in the event of sharp dips in demand occurring, thus likening the complete CSP with TES and ESS system to a fast dynamic, PHS plant. In a recent review by Akinyele and Rayudu [12] the authors present both the qualitative and quantitative properties of energy storage media and systems in general, with one section highlighting the limitations of some PHS in performing frequency regulation. 
It can be argued that a CSP with TES and ESS offers grid security by enabling such plants to supply robust grid stabilisation with infinitely variable and dispatchable power when other sources that cannot otherwise supply the demand effectively (akin to peaking-power plants) and like the PHS paradigm, could also capture excess energy when it's available from the grid thus enabling a better matching to sharp changes in grid demand.

Figure 2 presents a generalised model for investigations into the optimal partitioning of multiple TES and ESS elements. This model assumes that the TES is co-located with the collector and generator blocks but does not impose the same restriction on the ESS blocks. The ESS is assumed to be in the direct control of the CSP plant but could be implemented as downstream distributed storage within either the transmission or distribution networks.

Figure 2. A generalised system for the realisation of a concentrated solar power (CSP) with multiple tuned Thermal Energy Storage (TES) and Electrical Storage Systems (ESS) storage elements.

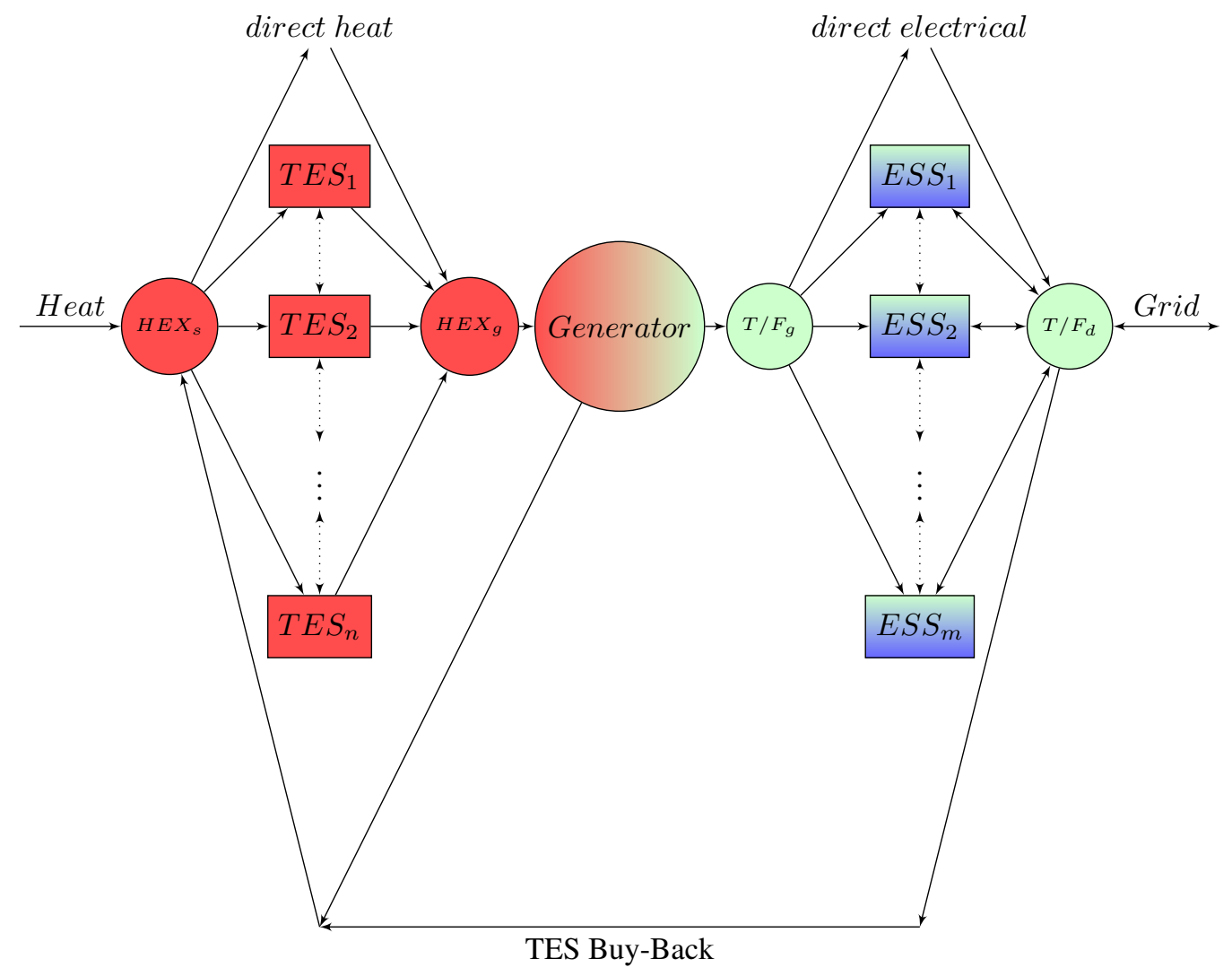

With reference to Figure 2 it is envisaged that a number or combinations of TES and ESS may be investigated for a particular CSP plant with the salient aspects for the formulation of the problem as follows:

$$
\begin{array}{lr}
Q_{T E S_{i} M a x} \ll Q_{T E S_{i+1} M a x} & \text { hierarcy of TES capacities } \\
T_{T E S_{i} M a x} \gg T_{T E S_{i+1} M a x} & \text { hierarcy of TES operating temperatures } \\
\dot{Q}_{T E S_{i} M a x} \gg \dot{Q}_{T E S_{i+1} M a x} & \text { hierarcy of TES responsivness } \\
C O S T_{T E S_{i}} \gg C O S T_{T E S_{i+1}} & \text { hierarcy of TES cost }
\end{array}
$$




$$
\begin{aligned}
& Q_{E S S_{j} M a x} \ll Q_{E S S_{j+1}} \text { Max } \quad \text { hierarcy of ESS capacities } \\
& \dot{Q}_{E S S_{j} M a x} \gg \dot{Q}_{E S S_{j+1} \text { Max }} \text { hierarcy of ESS responsivness } \\
& C O S T_{E S S_{j}} \gg C O S T_{E S S_{j+1}} \quad \text { hierarcy of ESS cost } \\
& \sum_{i=0}^{n} Q_{T E S_{i} \text { Max }} \gg \sum_{i=0}^{m} Q_{E S S_{j} \text { Max }} \text { comparative TES and ESS sizes }
\end{aligned}
$$

where the subscripts $i$ and $j$ are the indexes for each of the TES and ESS blocks of Figure 2 respectively with $m$ representing the total number of TES blocks and $n$ indicating the total number of ESS blocks. The different TES and ESS blocks would typically have different trade-offs between capacity, cost and performance alluded to with the hierarchical set of relationships above.

The aim of the research is to identify existing works applicable to demonstrating the energetic and economic benefits of a CSP system as depicted in Figure 2 not only to meet the present demands (if the opportunity should arise to implement such a system in the near future) but a number of "on the horizon" scenarios with varying RE and demand side management penetration being the motives for developing this article.

\subsection{Elements of Concentrating Solar Power with Storage}

\subsubsection{Solar Concentrators}

Figure 3, as taken from Figure 1 of [13], depicts the four main approaches for implementing the solar concentrator element of CSPs for thermal power generation. They are listed here in the order of current commercial deployment levels [14]:

(i) parabolic trough,

(ii) central receiver tower,

(iii) linear Fresnel and

(iv) paraboloidal dishes

The list above excludes configurations involving the focussing of DNI onto PV cells, referred to as Concentrated PV (CPV), achieved with a clear polycarbonate Fresnel lens in front of the PV cell or the mounting of PV cell receivers at the focus of paraboloidal dishes. As these configurations generate electricity directly without the opportunity to store the heat energy for delayed generation using TES devices, CPV configurations currently only use ESS storage although research into the use of TES for CSP may be transferable to CPV systems despite the current status of it only being compatible with ESS storage.

The low ecological impact of CSP does come with its own challenges, as stated before solar irradiation can be variable and unlike PV, which generates electricity from global or diffused solar radiation, CSP is limited to utilizing only the direct normal irradiation (DNI) component hence candidate sites should have low smog and dust levels as well as a high percentage of clear days as highlighted by Lovegrove and Stein [14]. A discussion relating to location in Section 3.06.7.1 of Hoffschmidt et al. [15] the authors present a lower bound for total DNI of 2000 kilowatt hours (kWh) per square meter, annually; sites achieving up to $2800 \mathrm{kWh} \cdot \mathrm{m}^{-2} \cdot \mathrm{year}^{-1}$ are termed "premium sites", with sites 
receiving $<6 \mathrm{kWh} \cdot \mathrm{m}^{-2}$. day $^{-1}$ being excluded outright, although this is circa $2200 \mathrm{kWh} \cdot \mathrm{m}^{-2} \cdot \mathrm{year}^{-1}$, it presents a lowest acceptable daily limit as presented by Leitner and Owens [16]. Further constraints are configuration specific with CSP utilising solar trough or linear Fresnel concentrators requiring an area minimum of $1 \mathrm{~km}^{2}$ with $1 \%$ flatness. Central tower receivers with heliostats can be erected smaller areas, "even in hilly regions" but cannot be operated at times of high wind hence precluding sites with frequent excessive wind gusts.

Figure 3. Schematics of the Four CSP Approaches for Power Generation (taken from Figure $1[13])$.

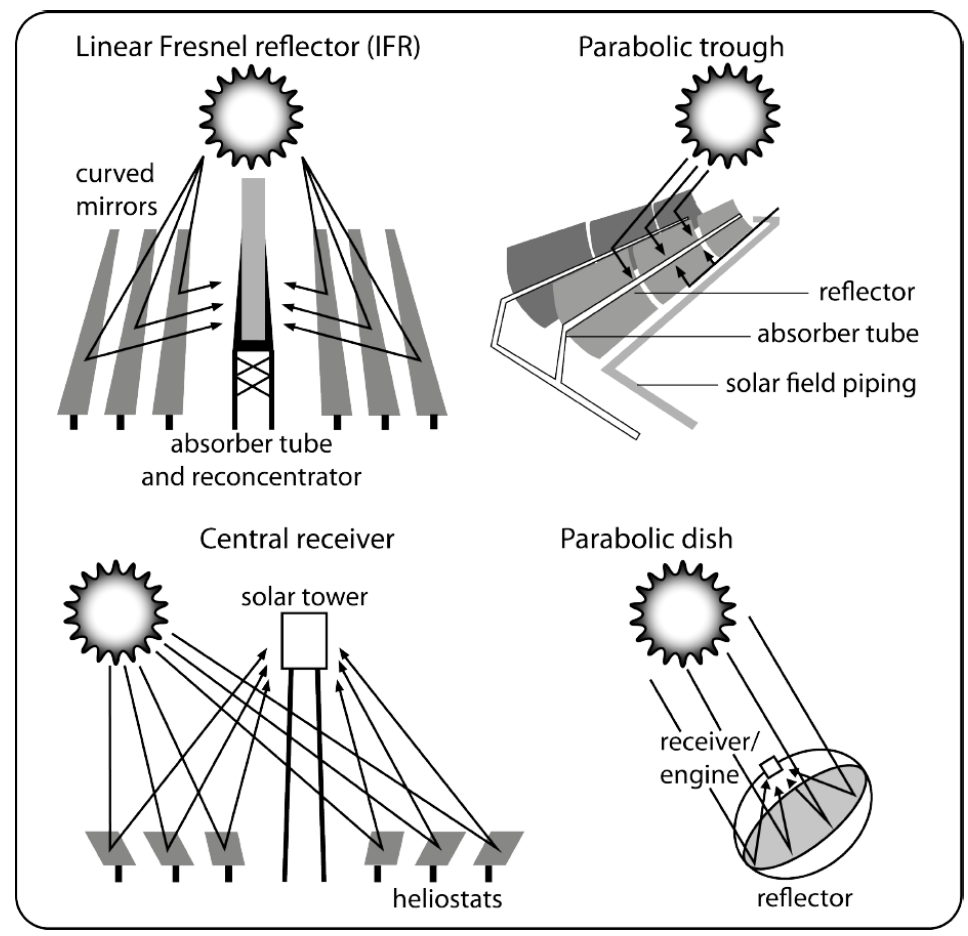

\subsubsection{Theoretical Limits on CSP System Efficiency}

Details of the theoretical and practical limits to efficiencies achievable with the various realisations of solar concentrators for the generation of electrical power are presented in detail by Lovegrove and Pye [1] and Hoffschmidt et al. [17] with the salient features presented herein. With reference to Figure 1 the overall system efficiency of a CSP plant using an adaptation of Equation 2.1 from [1] is given as:

$$
\eta_{\text {system }}=\eta_{\text {optical }} \times \eta_{\text {receiver }} \times \eta_{\text {transport }} \times \eta_{\text {thermal storage }} \times \eta_{\text {conversion }} \times \eta_{\text {electrical storage }}
$$

where

价tical

is the optical efficiency of the concentrator, which includes all losses up to but not including the receiver

is the receiver element efficiency, which includes any losses associated with the absorption and transfer of the concentrated energy available at the receiver 
$\eta_{\text {transport }}$

is the transport media efficiency, including any losses in downstream heat exchangers where different heat transfer fluids (HTF) are interfaced

$\eta_{\text {thermal storage }}$

is the combined charging and discharging efficiency of any TES element(s)

$\eta_{\text {conversion }}$

is the heat to electrical power conversion efficiency theoretically limited to the Carnot cycle efficiency for thermal-mechanical systems but in practice accounts for mechanical and electrical losses in the power block.

$\eta_{\text {electrical storage }}$

is the combined charging and discharging efficiency of any EES element(s), if used, incorporating any conversion losses for AC-DC and DC-AC conversion.

A simplified analysis for the theoretical limit for achieving maximum efficiency of a CSP is often presented as being a product of the receiver efficiency and the Carnot efficiency of the power block with all other efficiencies being ignored (or assumed to be 100\%). In a CSP system optimisation problem the nuances of each element and their interactions should not be ignored and as stated in [1]: the optimal system efficiency is not achievable by maximising each of the efficiencies expressed in Equation (1) separately. The following information is presented to provide a generalised qualitative overview on the theoretical limits imposed on CSP technologies.

Carnot efficiency $\left(\eta_{\text {Carnot }} \approx \eta_{\text {conversion }}\right)$ for the conversion of heat to mechanical work will constrain the overall system efficiency of any thermal-mechanical system. It is derived from the Second Law of Thermodynamics and can be expressed as a function of the highest $\left(T_{\text {High }}\right)$ conversion process temperature and lowest or ambient $\left(T_{\text {Low }}\right)$ temperature in degrees Kelvin $(K)$ for the thermal-mechanical system:

$$
\eta_{\text {Carnot }}=1-\frac{T_{\text {Low }}}{T_{\text {High }}}
$$

With simplified assumptions relating to the various losses in the receiver, its efficiency can be presented as given in [17]:

$$
\eta_{\text {receiver }}=\alpha_{\text {effective }}-\frac{\epsilon \sigma_{s} T^{4}}{C S}
$$

where

$\alpha_{\text {effective }}$ is the effective absorptivity of the receiver

$\epsilon$ is the emission coefficient for the receiver

$\sigma_{s}$ is the Stefan-Boltzmann constant, $5.670 \times 10^{-8} \mathrm{~W} \cdot \mathrm{m}^{-2} \cdot \mathrm{K}^{-4}$

$T$ is the receiver temperature in $K$

$C$ is the concentration factor given by:

$$
C=\frac{\text { collector aperature area }}{\text { receiver area }}
$$

$S$ is the solar input in $W \cdot \mathrm{tm}^{-2}$ 
The relationship between typical concentration factors, temperature at the receiver (or absorber) and maximum receiver efficiencies for different concentrator types is given in Table 1 and taken from observations made of Figure 1 of Hoffschmidt et al. [17]. Theoretical limits on concentration factors have also been described by Lovegrove and Pye [1] as being 215 for 2 dimensional line concentrators, such as solar trough or linear Fresnel receivers and 46,250 for 3 dimensional point-focus concentrators such as solar towers and paraboloid disc concentrators. These theoretical limits are then compromised from the ideal from factors such as geometry variances, non-ideal reflectivity of the collector material and variations in the shape of the solar disc as a result of dispersion from atmospheric particulates.

Table 1. Indicative values of concentration factor, receiver temperature at maximum efficiency for different concentrator types (as observed from adapting Figure 1 [17]).

\begin{tabular}{cccc}
\hline Reflector Type & Concentration Factor & $\boldsymbol{T}_{\text {absorber }}=\boldsymbol{T}_{\text {process }}(\boldsymbol{K})\left(\right.$ at $\left.\boldsymbol{\eta}_{\max }\right)$ & $\boldsymbol{\eta}_{\text {max }}$ \\
\hline Flat plate collector & 1 & $300 \mathrm{~K}$ & 0.08 \\
Parabolic Trough & $\approx 100$ & $720 \mathrm{~K}$ & 0.50 \\
Central Tower & $\approx 1000$ & $1120 \mathrm{~K}$ & 0.65 \\
Parabolic Dish & $\approx 4000$ & $1480 \mathrm{~K}$ & 0.72 \\
\hline
\end{tabular}

\subsubsection{Power Block Operation}

The text "Power Systems Analysis" by Saadat [18] presents the basic principles of power system generation, distribution, dispatch, fault tolerance, stability and control with MATLAB code for use with MATLAB, SIMULINK and Control System Toolbox. Chapters 1-6 deal with the basics of power generation and distribution. Chapter 7 deals directly with the cost to dispatch energy from a traditional fuel fired power station, stating that the operational cost of such a power plant is a quadratic function of the fuel cost; with CSP the cost of generation is largely driven by operation and maintenance activities.

Chapters 8-10 present transient analysis methods and fault condition management. Chapter 11 introduces the swing equation for output power $\left(P_{e}\right) v s$. power angle $\left(\delta_{e}\right)$ and equal area method for evaluating system stability capabilities, this analysis method may prove useful for sanity checking a design resulting from a stochastic analysis of solar resource, grid demand and market price perspectives. Finally Chapter 12 deals with power systems control applications and theory.

In Hoffschmidt et al. [17] the authors further detail the topology of a number of power block technologies as listed below:

\section{Steam Cycle}

the most common form of power generation using a variety of heat transfer fluids to generate steam for a generator turbine operating to a Rankine Cycle or variant thereof, 100s of MW of generation are possible in this configuration, with typical commercial CSP installations being $50 \mathrm{MW}$ and above.

\section{Organic Rankine Cycle}

use organic materials as the working fluid at lower working temperatures whilst still operating to a Rankine Cycle or variant thereof, for generation up to $10 \mathrm{MW}$. 


\section{Gas Turbines}

use a tower CSP in combination with a fuel fired combustion chamber to heat high pressure compressed air in order to drive a Brayton cycle power turbine, through the expansion of this heated air. The power turbine drives a primary generator and the air compressor used to provide the high pressure air. The expanded exhaust air is then used to heat a secondary steam cycle Rankine Cycle or variant thereof, steam turbine driven generator. No realisations of CSP augmented systems have been undertaken but conventional gas fired turbines used in this combined cycle configuration typically achieve 100s of MW of generation at the high conversion efficiencies.

\section{Solar Dish Sterling}

due to their high theoretical operation efficiencies paraboloid dishes have typically been implemented with Stirling cycle engines using hydrogen as a working fluid fitted directly to the receiver.

It is imagined that the details of the power block operation could be abstracted to a characterisation of the conversion efficiency $\left(\eta_{\text {conversion }}\right)$ and a quasi-static continuous time based function for energy conversion $\left(Q_{e}(t)\right)$. Such a model would accurately reflect the change of state for a power block over the time frames of interest (say 5 minute time intervals) without having to account for more dynamic transient response, in say the 10 second time frame.

\subsubsection{CSP Examples}

Example of implementations of CSP are presented in [17] with a partitioning of commercial and research plants being presented. A database of all current CSP Projects worldwide is maintained by the National Renewable Energy Laboratory (NREL) and SolarPACES organisations and is accessible at the website [19].

\subsubsection{Heat Transfer Fluids}

In order to transfer the heat available at the receiver block to the conversion block, either directly or indirectly through TES, heat transfer fluids (HTF) are used. A HTF can be a liquid, gas or in as is the case with steam for power generation or the refrigerant in a household refrigerator both, depending on where in the cycle you happen to look.

Heat exchangers (HEX) are required for the transfer heat from one HTF to another, say between the receiver media and the transfer media of the TES in Figure 1. Heat exchangers are constructed to maximise the heat transfer area whilst keeping each of the HTF separated and are usually constructed of highly conductive metals such as copper.

A common approach in CSP with two tank molten salt TES is to use the molten salt for the multiple purposes of receiver and transfer HTF as well as TES with only one set of heat exchangers between the molten salt HTF and the steam generators for the conversion block. This minimisation of heat exchanger elements is one of the common optimisation strategies employed in order to achieve greater conversion efficiencies as heat exchangers are material (and hence cost) intensive devices [1]. 


\subsubsection{Thermal Energy Storage}

Recent reviews of TES systems for use with CSP are presented in detail in both by Cabeza [20] and Steinmann [21]. Formulas pertaining to the thermodynamic behaviour of TES using Number of Transfer Units (NTU) are given in [20].

From these reviews there are three main categories of thermal energy storage: Sensible, latent and chemical.

Sensible storage involves materials storing heat in a given state be it solid or liquid. Solid concrete blocks and two tank molten salt systems are examples of sensible TES.

Phase Change Materials (PCM) offer a higher energy density (expressed in $\mathrm{kWh} / \mathrm{m}^{3}$ ) than sensible (or constant phase) TES. There are a number of possible phase change materials, these can involve a solid-solid transition as can occur in some polymer materials where chain alignment decreases as energy is stored; solid-liquid where the melting of a material constitutes energy storage and liquid-gas which often requires containment of the gas in a pressure vessel. A review of high temperature PCM suitable for CSP TES is given by Liu et al. [22], further more detailed formulations relating to the behaviour of PCM TES are given in Tay et al. [23] and Amin et al. [24], which builds on the work done by Belusko et al. [25].

$\epsilon$-NTU based characterisation approaches offer a simple method to modelling the turnaround efficiency $\left(\eta_{\text {transport }} \times \eta_{\text {thermal storage }}\right)$ of PCM TES elements and could be used in the formulation of TES storage characterisation. In Tay et al. [23] the average effectiveness $\epsilon \propto \eta_{\text {transport }} . \eta_{\text {thermal storage }}$ of a PCM thermal storage unit with phase change temperature $T_{P C M}$ is presented as follows:

$$
\epsilon=\frac{T_{\text {inlet }}-T_{\text {outlet }}}{T_{\text {inlet }}-T_{P C M}}=1-e^{-N T U}
$$

where $N T U$ can then be expressed as follows:

$$
N T U=\frac{U A}{\dot{m} C_{p}}=\frac{1}{R_{T} \dot{m} C_{p}}
$$

where

$U$ is the overall heat transfer coefficient in $W \cdot m^{-2} \cdot K^{-1}$

$A$ is the heat transfer area in $m^{2}$

$\dot{m}$ is the mass transfer rate of the (HTF) in $k g \cdot s^{-1}$

$C_{p}$ is the specific heat of the HTF $k J \cdot k g^{-1} \cdot K^{-1}$

$R_{T}$ is the total thermal resistance $W \cdot K^{-1}$

where $R_{T}=R_{H T F}+R_{\text {wall }}+R_{P C M}$

i.e., the sum of the HTF, heat exchange wall material and PCM resistances

From the above equations effectiveness $\epsilon=1-e^{-U A / \dot{m} C_{p}}$ so in order to keep storage effectiveness and hence efficiency high, mass flow rates must be minimised whilst maximising the heat transfer area between the HTF and PCM, with the implication that additional transfer area requires more material to implement and hence incurs greater cost.

There is potential for even higher energy densities from thermochemical storage which is still a topic of broad research. In this method heat is used to enact the endothermic reaction of a reversible 
chemical process, when the heat is later required the separated reagents are brought together to enact the exothermic process and recoup the stored energy. The separation of ammonia $\left(\mathrm{NH}_{3}\right)$ is discussed at length in [26].

Thermochemical storage could be analysed in detail, though a simplified generic model of storage considering turnaround efficiency $\left(\eta_{\text {transport }} \times \eta_{\text {thermal storage }}\right)$ and continuous time based function for energy storage state of charge $\left(\mathrm{SoC}, Q_{\text {thermal store }}(t)\right)$ may be sufficient.

\subsubsection{Electrical Storage Systems}

As stated above PV and wind based RE can only make use of ESS, Díaz-González et al. [27] and Chen et al. [28] provide a detailed reviews of ESS technologies which include capital costs as well as technical details, with Fthenakis and Nikolakakis [29] providing a more generalized overview of the technologies.

The broad categories of ESS are as follows:

Electro-mechanical electrical energy is used to perform mechanical work to store the energy, examples include:

Pumped Hydro Systems (PHS) Water from a lower level reservoir lake is pumped up to the higher reservoir for later use in the generation of energy

Compressed Air Energy Storage (CAES) Natural (air tight) caverns are pumped with compressed air for later energy recovery via decompression to atmospheric pressure

Flywheel Energy Storage Systems (FESS) A flywheel is spun-up to store energy and this increase in rotational momentum is then harvested to recoup the energy.

Electro-chemical energy is stored via changing the level of ionisation of a chemical electrolyte, examples include:

Battery Energy Storage Systems (BESS) there is a wide variety of battery technologies both in production and as topics of research. The main challenges with battery storage relate to limited useful life and the trade-off between the amount of storage used $v s$. battery life as is typical with Lead Acid batteries where the greater the Depth of Discharge (DoD) in any one cycle, the shorter the expected lifespan of the battery as a whole (expressed as the expected number of charge-dicharge cycles). Batteries offer large good energy storage capacity but are limited in the amount of power they can deliver. Key parameters for batteries are useful life (of the order of 1000s of cycles), capacity (Wh), maximum charge and discharge rates and the impact of DoD on useful life.

Capacitor and Super-Capacitor Storage Systems Capacitors offer a greater power capacity than batteries with only a limited amount of energy storage, the advent of super capacitors allows for utility sized solutions to be implemented. The useful life of super capacitors is of the order of $10^{6}$ cycles.

Electro-magnetic Superconductor Magnetic Energy Storage (SMES) stores via energising a superconductor coil. 
The use of ESS could be captured with a simplified generic model of storage considering turnaround efficiency ( $\left.\eta_{\text {electrical storage }}\right)$ and continuous time based function for energy storage state of charge (SoC), stated as follows:

$$
S o C_{e}(t)=Q_{e} \text { Stored }(t) / Q_{e} \max
$$

with

$$
\begin{array}{lr}
\dot{Q}_{e \text { Stored }}=\alpha Q_{e \text { Stored }} \text { for some constant } \alpha<0 \\
\ddot{Q}_{e \text { Stored }}>0 & \text { when discharging and } \\
\ddot{Q}_{e \text { Stored }}<0 & \text { when charging. }
\end{array}
$$

where

$S o C_{e}(t)$ is the State of Charge proportion

$Q_{e}$ Stored $(t)$ is the electrical energy stored in $W s$ or $J$

$\alpha$ is a negative the rate of charge/discharge constant

$Q_{e \max }$ is the maximum electrical energy capacity for the storage incorporating the efficiency factor $\eta_{\text {electrical storage }}$ in $W s$ or $J$, this implies that the actual electrical storage capacity will be $Q_{e \text { max }} / \eta_{\text {electrical storage }}$ and will need to be costed appropriately

\subsubsection{Electrical Buyback Heaters Installed Within TES}

Modelling and optimisation of a virtual CSP with two tank TES fitted with heaters enabling buy-back of energy is presented by Lizarraga-Garcia et al. [30]. The analysis demonstrated that under volatile price fluctuations electricity buy back provides added value to the system. Further concluding remarks indicate that Levelised Cost of Electricity (LCOE) is not a valid economic measure as it does not take into account opportunities for added profitability based on time of day (such as evening peak demand). This analysis did not take into account varying solar input and was optimised solely for a fixed power block operating under ideal irradiation and varying degrees of price volatility. Further discussion of economic metrics is presented in Section 2.3.4 of this article.

\subsection{Economic Environment}

\subsubsection{Australian Market Rules}

CSP electric power plants will operate within the context of Australia's National Energy Market as defined by the National Electricity Rules [3]. The NER provide the characterisation of participating generation plants of greater than $30 \mathrm{MW}$ as either scheduled, non-scheduled or semi-scheduled, with non-scheduled and semi-scheduled participants being RE generation (predominantly wind and PV). For semi-scheduled generators further requirements are imposed relating to the provision of generation models and the ability for the regulator to limit supply in times when the generation exceeds grid demand for safety or stability reasons. 


\subsubsection{Regulatory Structure}

Trading in the NEM is managed by the Australian Energy Market Operator (AEMO) [31].

The Australian Energy Market Commission (AEMC) [32] is responsible for the management of the National Energy Rules (NER) and advising of government as to proposed changes to them.

The Australian Energy Regulator (AER) [33] ensures participant compliance to NER for the wholesale electricity and gas markets within Australia.

\subsubsection{Regulator Data}

The AEMO Market data is available at [34] or to access the current and archived reports directly visit the ftp site at [35].

The AEMC report [8] discusses demand side management within the NEM and sets out an implementation plan as well as draft specifications for the roll out of this capability within the grid. Of the useful features of this report are the presentation of pilot studies and their results which are used in the development of the recommendations. The report also highlights the differing needs of Demand Side Participation (DSP) for a variety of consumers from residential to Commercial and Industrial (C\&I) customers.

\subsubsection{Economic Metrics}

The NREL report by Short et al. [36] provides a comprehensive list of metrics that can be called on in an economic analysis of RE projects. Arguably Levelised Cost of Energy (LCOE) though commonly used to compare the economic merits of a proposed or operating power generation plant may not be the best metric for a comparative assessment. A critique of LCOE from an economic perspective is presented by Joskow [37] where in a simple peak/offpeak period two price model it is highlighted that the return from wind generators in an open market will depend upon when the price at the time of generation. In a more recent report by Denholm et al. [9] in relation to plants that can generate revenue from providing generation reserve guarantee whether actual power is generated or not states:

"This is another example of the challenges of using energy-only metrics such as levelized cost of energy, LCOE; the most extreme example would be in the case of a device that sells only reserves and no real energy, where its value on an energy basis would effectively be infinite."

Any comparative analysis should use a selection of economic metrics in an attempt to find a better match for the true value of a CSP plant in different operational scenarios. Of these Annualised Cost, Internal Rate of Return and Net Present Value are a selection of the more common metrics (other than LCOE). The expression for NPV is one of the simpler metrics that may be used and is given below as for demonstration purposes:

$$
N P V=\sum_{i=1}^{N} \frac{C_{i}}{(1+\gamma)^{i}}
$$

where

NPV Net Present Value

$N$ number of investment years to current year 
$C_{i}$ all costs incurred during year $i$

$\gamma$ discount rate

The 2008 US Government report by Kaplan [38] documents the cost of electricity generation from all generator types at the time of publication. The breadth of this report allows for an objective assessment of CSP proposals against other technologies.

\subsection{Modelling and Optimisation: Methods Applicable to CSP with Storage}

Power generation of CSP with storage needs to be framed within the context of:

(a) the available solar resource, or DNI

(b) the energetic load or demand from the grid

(c) the economic environment

Optimisation of a CSP with storage needs to consider the following, with the most important first:

(a) scenarios pertaining to the operation of a CSP plant with varying percentage penetration of other stable or VG RE, from the current, up to $100 \%$ RE supply

(b) control paradigms for optimal dispatch of energy within these scenarios

(c) optimisation of the sizing of storage and any control parameter thresholds

When considering operational scenarios and control paradigms for CSP operation within the context of the Australian NEM energy and ancillary services dispatch bids are made at 5 minute intervals with half hourly clearing cycles. There is an apparent lack of research for methods related to operation in similar time frames or specific to the Australian NEM as such this is identified as possible contribution to the body of knowledge for any proposed research.

Table 2 is adapted from a number of sources and is presented in this survey in an attempt to align the terminology for energy forecasting and control.

Table 2. Nominal terminology for the time frames of energy forecasting and control.

\begin{tabular}{ccc}
\hline Term & Nominal Units & Nominal Range \\
\hline Very Short Term & minutes & seconds to hours \\
Short Term & hours & minutes to hours \\
Medium Term & days & hours to weeks \\
Long Term & months/years & months to years \\
\hline
\end{tabular}

\subsubsection{Models for Solar Irradiation}

The work performed by Huang et al. [39] gives an hourly one step ahead predictor for global or DNI solar irradiation provided there is historical training data available using a modified time series analysis method, this method is investigated further for half-hourly and 5-minute data in the PhD thesis by Huang [40]. Work has also been performed by Boland et al. [41] to establish the diffuse fraction of solar irradiation from which DNI can be inferred when only global solar irradiation historical data is 
available. For this reason any proposed research investigations should begin with sites where historical DNI data is available.

In Perez et al. [42] the author presents a temporal partitioning of solar irradiation prediction where 1-6 $\mathrm{h}$ ahead is considered to be short term and up to 6 day ahead is a medium term prediction. This paper also presents Numerical Weather Prediction (NWP) as used for the National Digital Forecast Database [43] being more accurate than other short term methods once the forecast horizon is greater than 3-4 h.

For Australia, Australian Community Climate and Earth-System Simulator (ACCESS) Numerical Weather Prediction (NWP) data made available by the Bureau of Meteorology. The document [44] gives details of the ACCESS data with a data overview at [45].

As the time frames for NWP predictions are short to medium term they may prove useful as the basis for real time decision making or operational strategy to ensure longer term demand can be met. In the review of solar irradiance models Diagne et al. [46] discuss the accuracy, computational requirements for predicting solar irradiance at various time horizons along with hybrid models for the combination of both very short term and longer term predictive models.

\subsubsection{Models of Demand}

A comprehensive review of demand modelling for use with energy production worldwide is presented by Suganthi and Samuel [47]. This review dealt with short term to long term forecasting world wide using a variety of techniques.

Modelling techniques for the synthetic generation of load or demand characteristics have been developed for South Australia by Magnano et al. [48]. Their previous work [49] was used to support this work as demand variation is largely driven by temperature and time of year. The main focus of this work was to accurately synthesise heat wave phenomena and the associated load demand experienced in South Australia. With Boland [50] building on both these previous works with two applications one being a PV optimisation problem using stochastic programming as described by Shapiro and Philpott [51].

Demand Density forecasting for South Australia is discussed by Hyndman and Fan [52]; here a bootstrap method is used to simulate the temperature, with other parameters such as calendar effects, demographic and economic variables being used to predict the demand densities for South Australia from 2008-09 out to 2018-19. A separation of industrial from residential load is also performed such that the trends in each can be modelled and analysed separately.

The PhD dissertation by Hong [53] discusses and describes short term load prediction using multiple linear regression methods based on month, hour, and temperature as the input variables. This work presented in the paper by Hong et al. [54]. Chapter 2 of [53] presents a broad review of short term load forecasting techniques where the two main stochastic methods identified by the author are regression or time series analysis and in the artificial intelligence domain Artificial Neural Networks (ANN), fuzzy logic and Support Vector Machine (SVM) methods are mentioned.

Of the methods above the work by Boland [50] could be used to synthesise demand for the initial evaluation of a control system, though a more complete study may make use of the other methods mentioned above in order to further validate the control system. 


\subsubsection{Models for Energy Spot Price Prediction}

The $\mathrm{PhD}$ thesis by Kim [55] presents a zero moment method for the prediction of spot price fluctuations applying the work done by Robbins and Monro [56] to the domain of energy markets. The results of this work are published in [57]. A recent review article by Weron [58] into the current status of energy market price prediction presents a comprehensive analysis of the various modelling and prediction methods in the literature to date. This review compares and contrasts the methods from a number of fields most notably those deemed to be from the field of Computational Intelligence, such as Artificial Neural Network methods and analytical methods based on statistical approaches.

An analysis of price fluctuations in the South Australian spot price will need to be conducted in order establish the most applicable method for the prediction of spot price and decision making for a CSP plant with storage.

In the absence of a more analytical approach a bootstrap method as used by Hyndman and Fan [52] may be used in the formulation of concurrent demand and price data in order to evaluate a control system.

\subsubsection{Modelling and Analyses with Scenarios of Differing Penetration of Renewable Energy}

Denholm et al. [9] build on [59] and discuss in some detail the operation of a CSP plant with storage within a scenario of $33 \%$ renewable energy supplier penetration. One of the main conclusions from this work was that CSP should be operated primarily to provide ancillary services for gird frequency stabilisation and ramp rate matching in order to provide maximum value to the grid in the $33 \% \mathrm{RE}$ penetration scenario.

This work utilises the NREL System Advisor Model (SAM) ([60,61]) physical through model described by Wagner and Gilman [62] for the solar concentrator sizing optimisation and operation of a solar trough system with storage and PLEXOS is one of many commercially available tools used for the modelling and evaluation of the grid behaviour and cost. A list of publications that describe other analyses performed with this tool is available at [63].

A complementary report by Mills and Wiser [64] compares the long-run marginal economic value of wind, single axis tracking PV, CSP without storage and CSP with 6 hours thermal storage in California for a 2030 scenario against the cost of operating a flat block fossil fuel generator of the same capacity, as the percentage penetration of all variable generation technologies is increased. The findings show that within the limited scope of their study, the marginal value of CSP with storage decreases less than that of PV and CSP without storage as the percentage penetration of variable generation increases and remains higher than that of wind at all penetration levels.

In Usaola [65] the author discusses similar grid stabilisation operation from a regulator or policy making perspective in the Spanish energy market with details of the model formulation and analyses presented in their work Usaola [5] for short term (2 day ahead) prediction of market behaviour (demand and price). One of the key findings of [65] is that the Spanish market does not present the same opportunities for returns as the US market.

For the Brazilian grid the work by Malagueta et al. [66] present a set of high level scenarios for the incorporation of large scale CSP giving a comparative analysis to enable policy decisions. 
The studies discussed above pertain to markets outside of Australia where both the day-do-day trading market mechanism and the incentives for capital investment differ. The report "Australian Companion Guide to SAM for Concentrating Solar Power", by Lovegrove et al. [67] documents the customisation required to NREL SAM in order for the plant operation to be evaluated in the Australian environment. The major drawback of the the modelling and evaluation discussed in the report is that plant output is evaluated to an hourly time frame although SAM can support evaluation of plant generation output to a 30 minute time scale given the appropriate weather and solar DNI data. It is suggested that a comparative analysis could draw from [67] for the financial metrics as a baseline for comparison.

\subsection{5. $100 \%$ Renewable Energy Scenarios}

There are many studies involving the analysis of $100 \% \mathrm{RE}$ generation some representative examples are given by Grossmann et al. [68], Jacobson and Delucchi [69] and Delucchi and Jacobson [70]. Grossmann et al. [68] presents analyses for interconnections at a global scale and analysed on a daily dispatch regime. The authors of [69] and [70] present a two part review and analysis of the available technologies, resources, infrastructure, costs and policies required for $100 \% \mathrm{RE}$ generation diversified across wind, wave and solar energy sources. In particular, the article [70] documents how the technological and spacial diversification of RE energy sources can smooth the supply of energy with flexible demand shifting and better forecasting allowing for better utilisation of the available resource.

The work by Barnhart and Benson [71] incorporates a broad discussion on the raw material resource availability requirement for a wide range electrical storage systems based on availability, energy density, embodied energy to make the end product and life span of the storage medium. A notable omission of this study is any discussion of TES. Chen et al. [28] offers a comparative analysis of more technologies where the cost of high temperature TES is stated as being the range of 30-60 \$/kWh with lifespan of 5-15 years. This cost excludes the generation equipment in order for energy conversion from heat to electricity to occur.

An analysis for theoretical 100\% RE penetration in the Australian NEM with performed by Elliston et al. [72] indicates that some level of biofuel gas fired generation will always be required in order to meet electricity demand, especially in winter. A notable omission of this work is the accounting of total winter energy use, as natural gas is commonly used for domestic winter heating within households connected to the NEM. This omitted energy requirement would need to be met from either additional electricity or biogas production during winter than was analysed in this paper. The modelling was based on hourly simulation and dispatch of energy based on a priority dispatching algorithm favouring indeterminate resources over those with storage with hydro and biogas having the lowest dispatch priority. Furthermore although this analysis works on the short term time base there is little or no discussion of the economic opportunities nor costs which the proposed research intends to address.

Elliston et al. [73] then builds on the previous work, [72] by incorporating a cost model and the ability to analyse the transfer of energy via regional interconnections for the 5 states in the NEM (namely South Australia, Queensland, New South Wales, Victoria and Tasmania) using the low cost and high cost estimates for generating equipment as given in the BREE report [74] for two different discount rates (5\% and 10\%). The model is implemented using Python programming language and evaluated using 
a Genetic Algorithm (GA) via the Pyevolve package of Perone [75] for minimising the total capital cost for meeting 2010 demand in a 2030 scenario of 100\% RE generation. This paper concludes with a comparison between replacement cost of existing fossil fuel based generation with either more of the same or $100 \%$ renewable fleet and concluding that for $5 \%$ discount rate there is equality for a carbon price of $\$ 50-\$ 65$ per tonne $\mathrm{CO}_{2}$-e going up to $\$ 75-\$ 100$ per tonne $\mathrm{CO}_{2}$-e for the $10 \%$ discount rate. Future work by this group of researchers will be focussed on further refining the model with more representative interconnections between generation and load centres.

The Draft Release AEMO report [76] details a set of four case studies for $100 \%$ RE generation based on one of two scenarios, one with rapid deployment and moderate economic growth the other with moderate deployment and rapid economic growth for projected demand in the year 2030 or 2050. Input data for the report is sourced from the "AEMO's Modelling Assumptions and Input Report" [77], with the modelling methodology involving a Monte Carlo probabilistic generation of demand, generation and storage with hourly dispatch and Demand Side Participation (DSP) or voluntary load shedding, with some of the relationships between these being based on historical data. Time-sequential modelling on an hourly time scale was then performed to establish "capacity sufficiency" or the ability to track demand and "energy sufficiency" the ability to deliver energy when intermittent supply is low, with one of the key findings being that the most challenging week would be experienced during winter. Each hourly evaluation was then reviewed or checked against transmission network data to evaluate grid performance and stability and re-evaluated if constraints were not met. Appendixes of “AEMO's Modelling Assumptions and Input Report" [77] of particular relevance to this article include the additional generation details of [77] Appendix 2, where modelling costs involved in RE generation are detailed, the criteria for CSP performance given in [77] Appendix 4 and the criteria pertaining to frequency regulation and grid stability in general, given in [77] Appendix 6.

One of the clearly stated limitation to the modelling of CSP with storage from [76] was to use all the energy stored in the previous 24 hours in the proceeding day without addressing possible consequence of this for the longer term, any proposed research should address this limitation by using medium term forecasting to adjust the CSP SoC amount from one day to the next in line with the expectation of longer duration weather patterns.

The work by Huva et al. [78] presents a regional assessment for 100\% RE generation where sites were selection was based on the results of Weather Research and Forecasting (WRF) model [79]). Optimisation of the system was performed in two phases, the first simple analysis for meeting demand with only a combination of wind and solar energy, followed up with a more complex analysis incorporating $2 \mathrm{GWh}$ of PHS as well as biogas backup in order to meet synthesised demand in all cases.

\subsubsection{Control Paradigms for Power Systems with Storage}

There exist a number of related control problems from which we can draw upon if not for the formulation of the problem of optimising storage explicitly but at least for the paradigms used. Of these the control of hybrid cars and the management of hydroelectric generator water reserves (both for outflow only generation and for PHS) were investigated. 


\subsubsection{Hybrid Cars}

The motor control for hybrid cars presents some parallels with power generation for the grid when utilising storage, in that electrical storage provides a buffer for the primary energy supply in the optimisation of total power output; In the work by Evangelou and Shukla [80] a simple control paradigm for hybrid car control with only four active states is presented. This work builds on the previous work by Shabbir et al. [81] to evaluate the off-line efficiency optimum for the supervisory control based on three different driving scenarios.

The control system for a CSP plant with storage could effectively be modelled in a similar way with a small set of control modes and where the state transition thresholds would be established based on a set of typical (or even worst case) supply, demand and price profiles and then evaluated against either synthetically generated series of data or in a real time environment.

\subsubsection{Hydroelectric Reservoir Management}

Hydroelectric power is one of the most mature RE technologies, although Green House Gas (GHG) emission free can have massive ecological impact on river valleys and water flows. Like CSP dependence on variable daily DNI levels, reservoir levels too are dependant on variable rainfall over the system catchment area over the course of a year. The text "Dynamic Programming Based Operation of Reservoirs" by Nandalal and Bogardi [82] is a comprehensive treatment of reservoir management techniques utilising Dynamic Programming (DP) in order to formulate and satisfy the many objectives that water reservoir systems may need to address such as energy supply as well as drinking water supply and quality.

It should be noted that DP problems are formulated as discrete both temporally (in time) as well as to the various system element states (reservoir level, unit of energy dispatched, etc.), and require considerable computational power in order to traverse the state space in search of optimal strategies. This body of knowledge may be of value in providing insight for the problem of managing storage for energy dispatch with CSP but from discussions with colleagues within the department may have limitations in providing sensible solutions for our particular problem.

\subsubsection{Optimisation for Renewable Electricity Generation and Storage}

The substantive review by Bazmi and Zahedi [83] for many aspects related to the optimisation problem for energy generation include optimisation methods as well as aspects of grid integration and stabilisation. A similar review by Baños et al. [84] points to a selection of papers in each of the RE generation domains mentioned in Section 2.1.1.

\subsubsection{Examples of Optimisation for Renewable Electricity Generation Operation}

Chapter 4 of the $\mathrm{PhD}$ thesis by Kim [55] presents a method to optimise the value of storage for an CSP plant via arbitrage for the dispatch of energy to the grid on a daily basis whilst making optimal very short term decisions throughout the day as to store or dispatch energy. The method is a modification of the news-vendor problem in operations research domain; the method assumes quantised state of 
charge levels for the storage element as well as operation within the discrete time domain. This work is published in [6].

The work by Powell and Edgar [85] uses simulation of the TES element for an initial demonstration of the benefits of using TES to overcome the problem of intermittent solar resource on cloudy days for a hybridised CSP with TES. Their follow on work [86] then deals with the dynamic optimisation of the hybrid CSP system with TES, where insufficient solar thermal power is supplemented with a fuel fired element with the complete system operation optimised in order to meet a constant 24 hour demand.

The work by Morin [2] presents an optimisation of a theoretical solar trough power plant with thermal store considering the multivariate objectives for economic, energetic and operational aspects. The method uses multi objective optimisation enabled via Genetic Algorithms (GA) for traversing the solution space and presents a sensitivity analysis on various aspects of the plant operation. From an economic perspective the method optimises an LCOE parameter and it is not clear how a very short term market price fluctuations are handled in the model if at all. The key finding of this work is that an interactive optimisation across all aspects of the plant, collector, power block and storage determines a better optimum that the optimisation of each of the components in isolation.

\subsubsection{Optimisation Under Uncertainty}

The review by Sharma et al. [87] presents an analysis of different stochastic methods for traversing problem domain, including stochastic variants of Genetic Algorithms (GA) and Particle Swarm Optimisation (PSO).

In the work by Yang et al. [88] a detailed assessment of a hybrid PV/Wind/BESS system with optimisation performed using GA based method where optimisation allowed for a minimum required loss of power supply probability (LPSP). The constrained LPSP approach of this analysis could be used in the formulation of CSP operation in a diversified RE generation scenario where RE generation from diverse locations and regions will be able to compensate for the shortfall of any one plant.

Channon and Eames [89] use dynamic programming is used to optimise the performance of plant in the Spanish OMEL energy market, where the output of the plant is linked to the bid prices in a day-ahead and within-day market.

The article by Ben-Tal and Nemirovski [90] and the subsequent book "Robust Optimisation" [91] present a complementary process to Stochastic Optimisation. More recently in [92] they further refine these methods by including a method that incorporates both "support (bounds on uncertainty of the true data point) and second order moments (mean and variance) of the uncertain training data points" to formulate a robust optimisation problem that is less conservative than when these are considered in isolation and tolerates errors in the estimation of both the support and second order moments.

Aspects of the problem optimisation may lend themselves to formulation as a robust linear program, especially if a parameter (variable, coefficient or constraint constant) can have small variations causing large changes to the objective function optimum. The any proposed research should endeavour to identify such parameters and may choose to investigate the use of this method in developing a robust optimum to the objective.

\section{Research Directions}




\subsection{Overview}

Directed research could be conducted in 3 major phases. The first, a preliminary analysis for an optimised CSP with storage at a single nominated location comparing it against the performance of existing systems such as transmission side inter-connector, peaking plant and as a complementary technology to existing residential PV and wind farms within South Australia. The findings from this work could then be generalised into a methodology that can be used to evaluate such systems at different and multiple sites with a final validation phase to ratify this generalised methodology.

The formulation and optimisation can be performed in two separate problem spaces in alignment with the real world paradigms of separating the design problem from the operation or "day-to-day" management of the plant. Hence there are at least two optimization problems which can be considered in isolation, the first being how an instantiation for the system is optimally operated or controlled in the time domain to optimise a given objective, such as achieving a maximum return with the second being how to size a plant given this optimal strategy.

\subsection{Preliminary Activities}

\subsubsection{Characterisation}

For an initial model parametrisation and validation a combination of synthetic sequences of DNI, demand and price data would be required. In the absence of synthetic data a bootstrap method may need to be implemented for the correlation of data from different sets, especially for demand and price from the methods identified for the synthesis of price for a given demand characteristic.

These sequences would be used to determine the energy surplus and shortfalls for the total demand as well as the nuances of the ancillary market demand characteristic (ramp rates and frequency stability) where a proposed CSP plant will supply a particular service to that demand.

A number of operational scenarios should be identified and based on these, a CSP plant can be designed in terms of collector size, TES, generator configuration and potentially ESS capacity. Initially we could use of simplified model for the CSP plant with storage that effectively models energy flows from one major component to the next with an efficiency penalty for each of the transfers to evaluate a daily process of consumption in establishing the optimal operational parameters (storage size, control thresh holds, etc.).

\subsubsection{Analysis}

A number of recent "actual days" and "ideal days" could be analysed to establish some preliminary metrics for the storage size an price performance of a proposed plant. The plant will be assumed to be small enough to not influence the price of supply whilst at the same time qualifying as either a scheduled or a semi-scheduled generator (using the definitions of Section 2 of the NER). As such a 30 MW plant that is a "price taker" as opposed to a "price maker" could be investigated in the current market with the analysis performed on a non-dimensional or per unit form so as to facilitate comparisons of performance and cost. 
To get a sense of how the interplay of irradiation (or more broadly energy supply), demand and price behaviour research should study the control of an ideal plant with storage for demand and price data of arbitrary summer and winter days, along with some extreme cases such as shortest day, hottest day and sequences involving cold spells and heat waves. From these preliminary investigations a target SoC for the storage may be established in order to maximise returns.

\subsubsection{Comparative Analysis Activities}

The characterisation phase discussed above may be performed for a number of operational scenarios to allow the comparison of such a plant to real/existing infrastructure utilisation:

Activity 1. Establish the Landscape using real data to determine effective parameters for operation as:

\section{(a) Demand Matching}

simply track demand and receive the current market clearing price for energy

(b) Heywood inter-connector

to guarantee high demand matching capability when energy flows from Victoria to South Australia.

(c) Peaking plant

Gas Fired Turbines such as those operated at the Osborne in South Australia utilised to meet demand peaks

(d) Wind support plant

where a CSP with electrically heated storage would support wind generation when either demand or supply is in excess

Activity 2. Using Stochastic Methods and Synthetic Data to demonstrate the robustness of the control paradigms developed in the previous task.

Activity 3. Parametric Analysis and cost optimisation for these limited scenarios, where the proposed system is exercised on the finer time-scale of half hourly market clearing and even 5 minute bidding cycle to further evaluate the performance of the control systems.

From this point control paradigms can be generalised from the insights garnered from the preliminary investigations and a more broad simulation can be undertaken to further validate the methods.

\subsection{Generalising the Methods}

In order to generalise the preliminary work there are may be a number of activities and collaborations required; the advice of specialist in thermodynamics, solar, wind and atmospheric modelling will enable the initial model to be refined in order to evaluate system performance at ever decreasing time scales and with forecasting both for short term, 5 minute one step ahead and medium term, between a day to a week ahead at more than one location.

Control strategy of the optimal dispatch of energy for a generator is expected to change as the RE generation penetration increases, especially if the diversity both in generator type and generation locations increases which will provide a natural "smoothing" to the energy supply, in much the same way as having diversity in the number and type of consumers smooths the demand profile. 
Validation of the modelling should be performed against both real and synthesised data with the results of optimisation to be compared against those of contemporary literature.

\section{Conclusions}

To date many analyses of CSP systems have involved detailed modelling of concentrator, storage and power block interaction with the environment; consisting of solar irradiation, electricity demand and spot price. This detailed approach can obfuscate the system behaviours and prevent the determination of the overarching optimal design and operational strategies for a CSP system operating in a deregulated market.

Whilst attempts to understand the key drivers using a sensitivity analysis of a CSP system in a techno-economic framework has identified some of the more sensitive parameters around a deterministic optimum, they cannot offer a confidence that the system will perform to this optimum in all or even a majority of operating conditions.

Other strategies within the literature are to abstract away some of the nuances of the particular RE source and then present an analysis on just one aspect, such as value of storage under an arbitrage paradigm. It can be argued that although this a valuable analysis a holistic model of the supply, demand and economic environment at the appropriate time scale to meet the short term spot price bidding requirements of the NEM would provide better insight into the value of a CSP with storage.

In this article a broad index of the technologies and methods utilised in the analysis and optimisation of CSP with Storage has been presented with a proposed outline for further research. Of the many methods used to optimise in the control of CSP with storage, stochastic and robust optimisation may offer novel approaches to deal with the inherent uncertainties of harnessing energy from a variable source to provide a time varying demand in an rapidly-changing energy distribution landscape. Any proposed research should allow for an improved more transparent understanding of the interplay of a CSP with storage in a deregulated electricity grid.

\section{Acknowledgments}

Luigi Cirocco would like to thank the financial support of the School of Information Technology and Mathematics and the Barbara Hardy Institute of the University of South Australia.

\section{Author Contributions}

Luigi Cirocco authored the this review article. Martin Belusko contributed specialist input for the $\epsilon$-NTU characterisations for PCM TES. Frank Bruno contributed specialist input for thermal storage systems for CSP. John Boland contributed specialist input regarding time series and stochastic modelling of renewable energy and demand variables. Peter Pudney contributed specialist input for the system model formulations and optimisation methods.

\section{Conflicts of Interest}

The authors declare no conflict of interest. 


\section{References}

1. Lovegrove, K.; Pye, J. Fundamental principles of concentrating solar power $\{(\mathrm{CSP})\}$ systems. In Concentrating Solar Power Technology: Principles, Developments and Applications; Lovegrove, K., Stein, W., Eds.; Woodhead Publishing: Philadelphia, PA, USA, 2012; Chapter 2, pp. 16-67.

2. Morin, G. Optimisation of concentrating solar power (CSP) plant designs through integrated techno-economic modelling. In Concentrating Solar Power Technology: Principles, Developments and Applications; Lovegrove, K., Stein, W., Eds.; Woodhead Publishing: Philadelphia, PA, USA, 2012; Chapter 16, pp. 495-535.

3. AEMC. National Electricity Rules: Current Rules. 2013. Available online: http://aemc.gov.au/Electricity/National-Electricity-Rules/Current-Rules.html (accessed on 10 October 2014).

4. Sayigh, A. Comprehensive Renewable Energy_Preface. In Comprehensive Renewable Energy; Sayigh, A., Ed.; Elsevier: Oxford, UK, 2012; pp. xx-xxii.

5. Usaola, J. Operation of concentrating solar power plants with storage in spot electricity markets. IET Renew. Power Gener. 2012, 6, 59-66.

6. Kim, J.H.; Powell, W.B. Optimal energy commitments with storage and intermittent supply. Oper. Res. 2011, 59, 1347-1360.

7. Cruise, J.; Flatley, L.; Gibbens, R.; Zachary, S. Optimal Control of Storage Incorporating Market Impact and with Energy Applications. Available online: http://arxiv.org/abs/1406.3653 (accessed on 10 October 2014).

8. AEMC. Power of Choice Review-Giving Consumers Options in the Way They Use Electricity. 2012. Available online: http://www.aemc.gov.au/market-reviews/open/power-of-choice-updatepage.html (accessed on 10 October 2014).

9. Denholm, P.; Wan, Y.H.; Hummon, M.; Mehos, M. An Analysis of Concentrating Solar Power with Thermal Energy Storage in a California 33\% Renewable Scenario; Technical Report NREL/TP-6A20-58186; National Renewable Energy Laboratory (NREL): Golden, CO, USA, 2013.

10. Syed, A. Australian Energy Projections to 2049-50. 2012. Available online: http://www.bree.gov.au/documents/publications/aep/Australian-Energy-Projections-to-2050.pdf (accessed on accessed on 10 October 2014).

11. Stanwix, G. Major Electricity Generation Projects. $2012 . \quad$ Available online: http://www.bree.gov.au/documents/publications/megp/ MajorElectricityGenerationProjectsNov2012.pdf (accessed on 10 October 2014).

12. Akinyele, D.; Rayudu, R. Review of energy storage technologies for sustainable power networks. Sustain. Energy Technol. Assess. 2014, 8, 74-91.

13. Bruno, F.; Saman, W.Y.; Liu, M. Concentrated solar power generation and high-temperature energy storage. In Creating Sustainable Communities in a Changing World; Roetman, P.E.J.; Daniels, C.B., Eds.; Crawford House Publishing: Belair, Australia 2011; Book 18, pp. 159-170. 
14. Lovegrove, K.; Stein, W. Introduction to concentrating solar power $\{(\mathrm{CSP})\}$ technology. In Concentrating Solar Power Technology: Principles, Developments and Applications; Lovegrove, K., Stein, W., Eds.; Woodhead Publishing: Philadelphia, PA, USA, 2012; Chapter 1, pp. 3-15.

15. Hoffschmidt, B.; Alexopoulos, S.; Göttsche, J.; Sauerborn, M.; Kaufhold, O. 3.06-High Concentration Solar Collectors. In Comprehensive Renewable Energy; Sayigh, A., Ed.; Elsevier: Oxford, UK, 2012; pp. 165-209.

16. Leitner, A.; Owens, B. Brighter than a Hundred Suns: Solar Power for the Southwest; Technical Report NREL/SR-550-33233; National Renewable Energy Laboratory (NREL): Golden, CO, USA, 2003.

17. Hoffschmidt, B.; Alexopoulos, S.; Rau, C.; Sattler, J.; Anthrakidis, A.; Boura, C.; O'Connor, B.; Hilger, P. 3.18-Concentrating solar power. In Comprehensive Renewable Energy; Sayigh, A., Ed.; Elsevier: Oxford, UK, 2012; pp. 595-636.

18. Saadat, H. Power System Analysis, 3rd ed.; PSA Publishing: Alexandria, VA, USA, 2010.

19. NREL and SolarPACES. Concentrating Solar Power Projects. 2013. Available online: http://www.nrel.gov/csp/solarpaces/ (accessed on 10 October 2014).

20. Cabeza, L.F. 3.07-Thermal Energy Storage. In Comprehensive Renewable Energy; Sayigh, A., Ed.; Elsevier: Oxford, UK, 2012; pp. 211-253.

21. Steinmann, W.D. Thermal energy storage systems for concentrating solar power (CSP) plants. In Concentrating Solar Power Technology: Principles, Developments and Applications; Lovegrove, K.; Stein, W., Eds.; Woodhead Publishing: Philadelphia, PA, USA, 2012; Chapter 11, pp. 362-394.

22. Liu, M.; Saman, W.; Bruno, F. Review on storage materials and thermal performance enhancement techniques for high temperature phase change thermal storage systems. Renew. Sustain. Energy Rev. 2012, 16, 2118-2132.

23. Tay, N.H.S.; Belusko, M.; Bruno, F. An effectiveness-NTU technique for characterising tube-in-tank phase change thermal energy storage systems. Appl. Energy 2012, 91, 309-319.

24. Amin, N.A.M.; Belusko, M.; Bruno, F.; Liu, M. Optimising PCM thermal storage systems for maximum energy storage effectiveness. Sol. Energy 2012, 86, 2263-2272.

25. Belusko, M.; Halawa, E.; Bruno, F. Characterising PCM thermal storage systems using the effectiveness-NTU approach. Int. J. Heat Mass Transf. 2012, 55, 3359-3365.

26. Lovegrove, K.; Luzzi, A.; Soldiani, I.; Kreetz, H. Developing ammonia based thermochemical energy storage for dish power plants. Sol. Energy 2004, 76, 331-337.

27. Díaz-González, F.; Sumper, A.; Gomis-Bellmunt, O.; Villafáfila-Robles, R. A review of energy storage technologies for wind power applications. Renew. Sustain. Energy Rev. 2012, 16, 2154-2171.

28. Chen, H.; Cong, T.N.; Yang, W.; Tan, C.; Li, Y.; Ding, Y. Progress in electrical energy storage system: A critical review. Prog. Nat. Sci. 2009, 19, 291-312.

29. Fthenakis, V.M.; Nikolakakis, T. 1.11-Storage options for photovoltaics. In Comprehensive Renewable Energy; Sayigh, A., Ed.; Elsevier: Oxford, UK, 2012; pp. 199-212. 
30. Lizarraga-Garcia, E.; Ghobeity, A.; Totten, M.; Mitsos, A. Optimal operation of a solar-thermal power plant with energy storage and electricity buy-back from grid. Energy 2013, 51, 61-70.

31. AEMO. Australian Energy Market Operator (AEMO) website. Available online: http://www.aemo.com.au (accessed on 10 October 2014).

32. AEMC. Australian Energy Market Commision (AEMC) website. Available online: http://www.aemc.gov.au (accessed on 10 October 2014).

33. AER. Australian Energy Regulator (AER) website. Available online: http://www.aer.gov.au (accessed on 10 October 2014).

34. AEMO. Australian Energy Market Operator (AEMO) market data. Available online: http://www.aemo.com.au/Electricity/Data (accessed on 10 October 2014).

35. AEMO. Australian Energy Market Operator (AEMO) market reports. Available online: http://www.nemweb.com.au/Reports/ (accessed on 10 October 2014).

36. Short, W.; Packey, D.J.; Holt, T. A Manual for the Economic Evaluation of Energy Efficiency and Renewable Energy Technologies; Technical Report NREL/TP-462-5173; National Renewable Energy Laboratory: Golden, CO, USA, 1995.

37. Joskow, P.L. Comparing the costs of intermittent and dispatchable electricity generating technologies. Am. Econ. Rev. 2011, 101, 238-241.

38. Kaplan, S. Power Plants: Characteristics and Costs; Congressional Research Service Report for Congress; United States Congress: Washington, DC, USA, 2008.

39. Huang, J.; Korolkiewicz, M.; Agrawal, M.; Boland, J. Forecasting solar radiation on an hourly time scale using a Coupled AutoRegressive and Dynamical System (CARDS) model. Sol. Energy 2013, 87, 136-149.

40. Huang, J. Forecasting Wind and Solar Energy on Short Time Scales. Ph.D. Thesis, University of South Australia, South Australia, Australia, 2013.

41. Boland, J.; Ridley, B.; Brown, B. Models of diffuse solar radiation. Renew. Energy 2008, 33, 575-584.

42. Perez, R.; Kivalov, S.; Schlemmer, J.; Hemker, K., Jr.; Renné, D.; Hoff, T.E. Validation of short and medium term operational solar radiation forecasts in the US. Sol. Energy 2010, 84, 2161-2172.

43. National Weather Service (USA). The National Forecast Database (NDFD). 2013. Available online: http://www.weather.gov/ndfd/ (accessed on 10 October 2014).

44. NMOC. Operational Implementation of the ACCESS Numerical Weather Prediction Systems; Operations Bulletin 83; National Meteorological \& Oceanographic Centre (NMOC): Melbourne, Australia, 2010.

45. BOM. ACCESS NWP Data Information; Available online: http://www.bom.gov.au/nwp/doc/access/NWPData.shtml (accessed on 10 October 2014).

46. Diagne, M.; David, M.; Lauret, P.; Boland, J.; Schmutz, N. Review of solar irradiance forecasting methods and a proposition for small-scale insular grids. Renew. Sustain. Energy Rev. 2013, $27,65-76$.

47. Suganthi, L.; Samuel, A.A. Energy models for demand forecasting-A review. Renew. Sustain. Energy Rev. 2012, 16, 1223-1240. 
48. Magnano, L.; Boland, J.W.; Hyndman, R.J. Generation of synthetic sequences of half-hourly temperature. Environmetrics 2008, 19, 818-835.

49. Magnano, L.; Boland, J.W. Generation of synthetic sequences of electricity demand: Application in South Australia. Energy 2007, 32, 2230-2243.

50. Boland, J.W. Generation of synthetic sequences of electricity demand with applications. In Uncertainty and Environmental Decision Making; Filar, J.A., Haurie, A., Eds.; Springer: New York, NY, USA, 2010; Volume 138, pp. 275-314.

51. Shapiro, A.; Philpott, A. A Tutorial on Stochastic Programming. 2007. Available online: http://www2.isye.gatech.edu/people/faculty/Alex_Shapiro/TutorialSP.pdf (accessed on 10 October 2014).

52. Hyndman, R.J.; Fan, S. Density forecasting for long-term peak electricity demand. Power Syst. IEEE Trans. 2010, 25, 1142-1153.

53. Hong, T. Short Term Electric Load Forecasting. Ph.D. Thesis, North Carolina State University, North Carolina, NC, USA, 2010.

54. Hong, T.; Wang, P.; Willis, H.L. A naïve multiple linear regression benchmark for short term load forecasting. In Proceedings of the 2011 IEEE Power Energy Society General Meeting, San Diego, CA, USA, 24-29 July 2011; pp. 1-6.

55. Kim, J.H. Quantile Optimization in the Presence of Heavy-tailed Stochastic Processes, and an Application to Electricity Markets. Ph.D. Thesis, Princeton University, New Jersey, NJ, USA, 2011.

56. Robbins, H.; Monro, S. A stochastic approximation method. Ann. Math. Stat. 1951, 22, 400-407.

57. Kim, J.H.; Powell, W.B. An hour-ahead prediction model for heavy-tailed spot prices. Energy Econ. 2011, 33, 1252-1266.

58. Weron, R. Electricity price forecasting: A review of the state-of-the-art with a look into the future. Int. J. Forecast. 2014, 30, 1030-1081.

59. Denholm, P.; Hummon, M. Simulating the Value of Concentrating Solar Power with Thermal Energy Storage in a Production Cost Model; Technical Report NREL/TP-6A20-56731; National Renewable Energy Laboratory: Golden, CO, USA, 2012.

60. Gilman, P.; Blair, N.; Mehos, M.; Christensen, C.; Janzou, S.; Cameron, C. Solar Advisor Model: User Guide for Version 2.0; Technical Report NREL/TP-670-43704; National Renewable Energy Laboratory: Golden, CO, USA, 2008.

61. Gilman, P.; Dobos, A. System Advisor Model, SAM 2011.12.2: General Description; Technical Report NREL/TP-6A20-53437; National Renewable Energy Laboratory: Golden, CO, USA, 2012.

62. Wagner, M.; Gilman, P. Technical Manual for the SAM Physical Trough Model; Technical Report NREL/TP-5500-51825; National Renewable Energy Laboratory (NREL): Golden, CO, USA, 2011.

63. Energy Exemplar. PLEXOS Publications; Available online: http://energyexemplar.com/publications/ (accessed on 10 October 2014).

64. Mills, A.; Wiser, R. Changes in the Economic Value of Variable Generation at High Penetration Levels : A Pilot Case Study of California; Technical Report June; Ernest Orlando Lawrence Berkeley National Laboratory: California, CA, USA, 2012. 
65. Usaola, J. Participation of $\{\mathrm{CSP}\}$ plants in the reserve markets: A new challenge for regulators. Energy Policy 2012, 49, 562-571.

66. Malagueta, D.; Szklo, A.; Soria, R.; Dutra, R.; Schaeffer, R.; Moreira Cesar Borba, B.S. Potential and impacts of Concentrated Solar Power (CSP) integration in the Brazilian electric power system. Renew. Energy 2014, 68, 223-235.

67. Lovegrove, K.; Franklin, S.; Elliston, B. Australian Companion Guide to SAM for Concentrating Solar Power; Technical Report May; Australian Solar Thermal Energy Association (Austela): Sydney, Australia, 2013.

68. Grossmann, W.D.; Grossmann, I.; Steininger, K.W. Distributed solar electricity generation across large geographic areas, Part I: A method to optimize site selection, generation and storage. Renew. Sustain. Energy Rev. 2013, 25, 831-843.

69. Jacobson, M.Z.; Delucchi, M.A. Providing all global energy with wind, water, and solar power, Part I: Technologies, energy resources, quantities and areas of infrastructure, and materials. Energy Policy 2011, 39, 1154-1169.

70. Delucchi, M.A.; Jacobson, M.Z. Providing all global energy with wind, water, and solar power, Part II: Reliability, system and transmission costs, and policies. Energy Policy 2011, 39, 1170-1190.

71. Barnhart, C.J.; Benson, S.M. On the importance of reducing the energetic and material demands of electrical energy storage. Energy Environ. Sci. 2013, 6, 1083-1092.

72. Elliston, B.; Diesendorf, M.; MacGill, I.C. Simulations of scenarios with $100 \%$ renewable electricity in the Australian National Electricity Market. Energy Policy 2012, 45, 606-613.

73. Elliston, B.; MacGill, I.; Diesendorf, M. Least cost $100 \%$ renewable electricity scenarios in the Australian National Electricity Market. Energy Policy 2013, 59, 270-282.

74. BREE. Australia Energy Technology Assessment. 2012. Available online: http://www.bree.gov.au/ documents/publications/aeta/Australian_Energy_Technology_Assessment.pdf (accessed on 10 October 2014).

75. Perone, C.S. Pyevolve: A Python open-source framework for genetic algorithms. SIGEVOlution 2009, 4, 12-20.

76. AEMO. 100 Per Cent Renewables Study_Draft Modelling Outcomes. 2013. Available online: http://www.climatechange.gov.au/sites/climatechange/files/files/reducing-carbon/aemo/ renewables-study-report-draft-20130424.pdf (accessed on 10 October 2014).

77. AEMO. AEMO's Modelling Assumptions and Input Report; Australian Energy Market Operator: Sydney, Australia, 2012.

78. Huva, R.; Dargaville, R.; Caine, S. Prototype large-scale renewable energy system optimisation for Victoria, Australia. Energy 2012, 41, 326-334.

79. Skamarock, W.C.; Klemp, J.B.; Dudhia, J.; Gill, D.O.; Barker, D.M.; Wang, E.; Powers, J.G. Description of the Advanced Research WRF Version 2. Available online: http://www.wrf-model.org/index.php (accessed on 10 October 2014).

80. Evangelou, S.A.; Shukla, A. Advances in the modelling and control of series hybrid electric vehicles. In Proceedings of the American Control Conference (ACC), Montreal, QC, Canada, 27-29 June 2012; pp. 527-534. 
81. Shabbir, W.; Arana, C.; Evangelou, S.A. Series hybrid electric vehicle supervisory control based on off-line efficiency optimization. In Proceedings of the 2012 IEEE International Electric Vehicle Conference (IEVC), Greenville, SC, USA, 4-8 March 2012; pp. 1-5.

82. Nandalal, K.D.W.; Bogardi, J.J. Dynamic Programming Based Operation of Reservoirs; International Hydrology Series; Cambridge University Press: Cambridge, UK, 2007.

83. Bazmi, A.A.; Zahedi, G. Sustainable energy systems: Role of optimization modeling techniques in power generation and supply-A review. Renew. Sustain. Energy Rev. 2011, 15, 3480-3500.

84. Baños, R.; Manzano-Agugliaro, F.; Montoya, F.G.; Gil, C.; Alcayde, A.; Gómez, J. Optimization methods applied to renewable and sustainable energy: A review. Renew. Sustain. Energy Rev. 2011, 15, 1753-1766.

85. Powell, K.M.; Edgar, T.F. Modeling and control of a solar thermal power plant with thermal energy storage. Chem. Eng. Sci. 2012, 71, 138-145.

86. Powell, K.M.; Hedengren, J.D.; Edgar, T.F. Dynamic optimization of a hybrid solar thermal and fossil fuel system. Sol. Energy 2014, 108, 210-218.

87. Sharma, N.; Varun; Siddhartha Stochastic techniques used for optimization in solar systems: A review. Renew. Sustain. Energy Rev. 2012, 16, 1399-1411.

88. Yang, H.; Zhou, W.; Lu, L.; Fang, Z. Optimal sizing method for stand-alone hybrid solar-wind system with LPSP technology by using genetic algorithm. Sol. Energy 2008, 82, 354-367.

89. Channon, S.; Eames, P. The cost of balancing a parabolic trough concentrated solar power plant in the Spanish electricity spot markets. Sol. Energy 2014, 110, 83-95.

90. Ben-Tal, A.; Nemirovski, A. Robust optimization-Methodology and applications. Math. Program. 2002, 92, 453-480.

91. Ben-Tal, A.; Laurent, E.G.; Nemirovski, A. Robust Optimization, 1st ed.; Princeton University Press: Princeton, NJ, USA, 2009; p. 565.

92. Ben-Tal, A.; Bhadra, S.; Bhattacharyya, C.; Saketha Nath, J. Chance constrained uncertain classification via robust optimization. Math. Program. 2011, 127, 145-173.

(c) 2014 by the authors; licensee MDPI, Basel, Switzerland. This article is an open access article distributed under the terms and conditions of the Creative Commons Attribution license (http://creativecommons.org/licenses/by/4.0/). 